\title{
Profiling Cloud Ice Mass and Particle Characteristic Size from Doppler Radar Measurements
}

\author{
SERGEY Y. MATROSOV \\ Cooperative Institute for Research in Environmental Sciences, University of Colorado, and \\ NOAA Environmental Technology Laboratory, Boulder, Colorado \\ Alexei V. KoroleV \\ Atmospheric Environment Service, Downsview, Ontario, Canada \\ ANDREW J. HEYMSFIELD \\ National Center for Atmospheric Research, Boulder, Colorado
}

(Manuscript received 16 May 2001, in final form 26 October 2001)

\begin{abstract}
A remote sensing method is proposed for the retrievals of vertical profiles of ice cloud microphysical parameters from ground-based measurements of radar reflectivity and Doppler velocity with a vertically pointed cloud radar. This method relates time-averaged Doppler velocities (which are used as a proxy for the reflectivity-weighted particle fall velocities) to particle characteristic sizes such as median or mean. With estimated profiles of particle characteristic size, profiles of cloud ice water content (IWC) are then calculated using reflectivity measurements. The method accounts for the intrinsic correlation between particle sizes and parameters of the fall velocity-size relations. It also accounts for changes of particle bulk density with size. The range of applicability of this method encompasses ice-phase clouds and also mixed-phase clouds that contain liquid drops, which are small compared to ice particles, so the radar signals are dominated by these larger particles. It is, however, limited to the observational situations without strong up- and downdrafts, so the residual of mean vertical air motions is small enough compared to the reflectivity-weighted cloud particle fall velocities. The Doppler-velocity reflectivity method was applied to the data obtained with an 8.6- $\mathrm{mm}$ wavelength radar when observing Arctic clouds. Typical retrieval uncertainties are about $35 \%-40 \%$ for particle characteristic size and $60 \%-70 \%$ for IWC, though in some cases IWC uncertainties can be as high as factor of 2 (i.e., $-50 \%,+100 \%$ ). Comparisons with in situ data for one observational case yielded $25 \%$ and $55 \%$ differences in retrieved and in situ estimates of characteristic size and IWC, respectively. The results of the microphysical retrievals obtained from the remote sensing method developed here were compared with data obtained from the multisensor technique that utilizes combined radarIR radiometer measurements. For pure ice-phase layers unobstructed by liquid clouds (i.e., conditions where the multisensor approach is applicable), the relative standard deviations between the results of both remote sensing approaches were about $27 \%$ for mean particle size and $38 \%$ for IWC, with relative biases of only $5 \%$ and $20 \%$, respectively.
\end{abstract}

\section{Introduction}

Many modeling studies indicate that clouds play a very important role in the earth's climate system and hydrological cycle (e.g., Ramanathan et al. 1989). Though the importance of clouds is widely recognized, their quantitative representation in climate models is still not adequate (Houghton et al. 1995). Clouds influence the earth's shortwave and longwave radiation budget by processes of scattering, absorption, and emission. The magnitude of cloud effects depends on cloud geomet-

Corresponding author address: Sergey Y. Matrosov, R/ET7, 325 Broadway, Boulder, CO 80305.

E-mail: Sergey.Matrosov@noaa.gov rical (i.e., fraction, thickness, altitude) and microphysical properties (Stephens et al. 1990). Among the most important microphysical properties of clouds for determining their radiative properties are cloud mass liquid water content (LWC) and ice water content (IWC) and cloud particle sizes. It is customary to describe cloud particle sizes by some characteristic size that represents the whole cloud particle size distribution (e.g., mean size, median size, etc.).

Though the information on cloud layer mean values of microphysical parameters is very helpful for quantitative representation of clouds in models, vertical profiles of these parameters are of a greater interest since they determine where in the atmosphere actual heating/ cooling due to clouds occurs. One way to acquire in- 
formation about profiles of cloud microphysics is from remote sensing methods that use measurements of active sensors (e.g., millimeter wavelength radars, lidars) that provide vertically resolved data.

During the last decade or so, a number of groundbased remote sensing methods have been suggested for cloud microphysical retrievals. The simplest radar-based methods use empirical relations between principal measurable radar reflectivity, $Z_{e}$, and a particular cloud parameter such as IWC or LWC (e.g., Liu and Illingworth 2000; Sassen 1987; Liao and Sassen 1994). The main advantage of these methods is their simplicity; however, their accuracy is limited, since reflectivity and cloud parameters do not relate to each other in a one-to-one manner. Thus, these empirical relations reflect only an average correspondence.

It is believed that a more robust way to retrieve cloud parameters is to apply a multisensor approach when measurements from several remote sensors are used in the retrieval scheme. For the layer-average retrievals of ice clouds, the combinations of radar reflectivity and infrared (IR) radiometer brightness have been used to retrieve mean values of IWC and particle characteristic size (Matrosov et al. 1992; Mace et al. 1998). This approach has been expanded for retrievals of vertical profiles of these cloud parameters (Matrosov 1997, 1999). Combinations of lidar and radar backscatter profiles (e.g., Intrieri et al. 1993; Donovan et al. 2001a,b), lidar and radiometer data (e.g., Platt and Dilley 1981), and radar backscatter profiles at different wavelengths (e.g., Sekelsky et al. 1999) also have been suggested for such retrievals. The use of several radar wavelengths, however, is limited only for the clouds with rather large particles when the scattering for at least one radar wavelength is outside the Rayleigh regime approximation.

The use of optical and/or IR wavelength sensors (i.e., lidars, radiometers) along with radars offers considerable insights into cloud microphysics. The corresponding remote sensing approaches, however, are limited mostly to ice-phase clouds that are not optically opaque. An additional and significant problem arises from the fact that cloud geometrical boundaries are seen differently by sensors operating at different wavelengths (Intrieri et al. 2002). Depending on their sensitivity, radars often do not "see" parts of clouds with very small particles, which could still be responsible for optical or IR signals.

Relatively recently, microphysical retrieval approaches have been suggested that rely solely on the use of the Doppler radar data. These approaches utilize measurements of either the whole Doppler power spectrum (e.g., Babb et al. 1999) or just its few moments (Matrosov et al. 2000; Fu et al. 2000). In some respects, such remote sensing techniques have their own advantages. One of them is that the information in the multiparameter retrievals comes from the same geometrical cloud boundaries, as they are seen by radar; thus, possible retrieval errors due to different "views" of a cloud by different remote sensors are eliminated. Cloud radar signals are "weighted" more strongly by the larger particles so that in a nonprecipitating mixed-phase cloud, radar Doppler estimates will be mostly representative of the ice particles because they are usually significantly larger than liquid drops. Thus the retrieval results will provide the information about the ice-phase component of a mixed-phase cloud.

In this study, we suggest a method to retrieve vertical profiles of IWC and ice particle characteristic size based on measurements of radar reflectivity $Z_{e}$ and Doppler velocity $V_{D}$ at vertical incidence. The proposed method is applied to pure-ice- and mixed-phase clouds, and the retrieval results are compared to in situ measurements of cloud microphysics. For pure-ice-phase clouds, the proposed method is compared to the radar-radiometer microphysical retrieval approach.

\section{Estimation of ice particle characteristic size from Doppler velocity measurements}

\section{a. Fall velocity-size relations}

For an individual ice cloud particle with size $D$ (for a nonspherical particle, its size is usually given as a particle dimension along some fixed direction of an optical probe or as its maximum dimension), a parameterized expression for the terminal fall velocity, $v_{t}$, can be represented by a power law (Mitchell 1996; Heymsfield and Iaquinta 2000):

$$
v_{t}=A D^{B} .
$$

The coefficient $A$ in (1) exhibits a significant range of variability depending, in part, on particle size (i.e., larger particles are characterized by smaller values of $A$ ). The exponent $B$ mostly varies between about 0.70 and 1.4. There is a close relation, however, between $A$ and $B$ in (1), which can be given as (Matrosov and Heymsfield 2000)

$$
B \approx 0.17 A^{0.24} \quad \text { (cgs units). }
$$

For an ensemble of cloud particles, the first moment of the Doppler spectrum (i.e., the reflectivity-weighted fall velocity $V_{z}$ ) is defined as

$$
V_{Z}=\frac{\int_{0}^{D_{\max }} v_{t} S_{z}\left(v_{t}\right) d v_{t}}{\int_{0}^{D_{\max }} S_{z}\left(v_{t}\right) d v_{t}}
$$

where $S_{z}$ is the Doppler spectrum in the velocity domain [note that the denominator in (3) represents the reflectivity factor, $Z_{e}$, which is often referred to in literature just as reflectivity]. Using (1), $V_{Z}$ can also be approximated by a power-law equation in terms of some characteristic particle size representing the whole particle size distribution, such as the median volume size $D_{0}$ (Matrosov and Heymsfield 2000): 


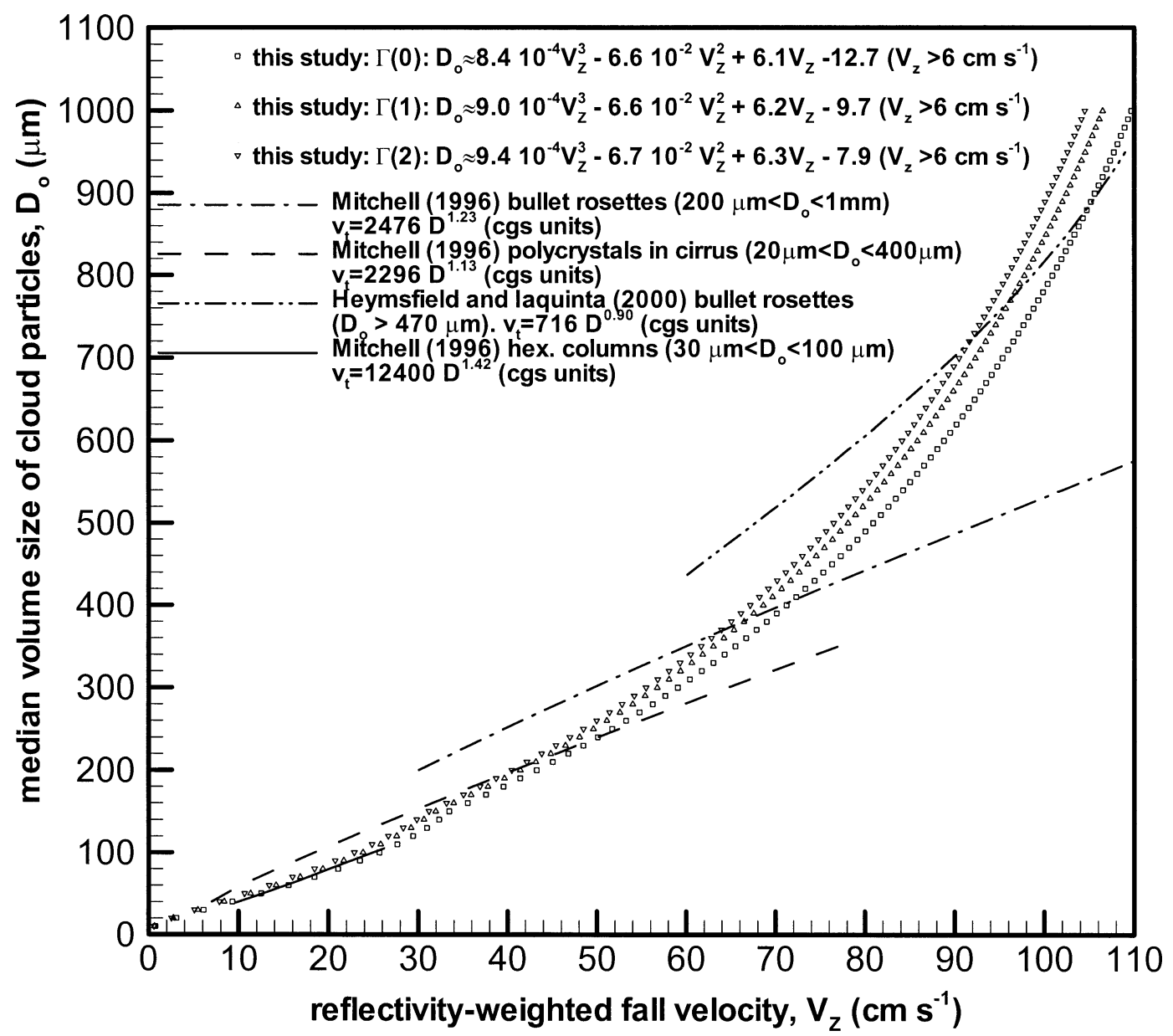

FIG. 1. Plotted symbols show mean relations from (4) between $D_{0}$ and $V_{z}$ for the gamma-function particle size distributions for $n=1$ (squares), $n=2$ (triangles), and $n=3$ (inverted triangles). Lines show results of calculations using data from Mitchell (1996) and Heymsfield and Iaquinta (2000) with constant values of $A$ and $B$ for size ranges of their validity. The best polynomial fit for the different values of $n$ is given at the top of the figure.

$$
V_{Z}=A a_{1} D_{0}^{B},
$$

where the coefficient $a_{1}$ depends mostly on the details of the particle size distribution (PSD). The transformation of the terminal velocity-size relation for an individual particle to one for the ensemble of particles (in terms of the reflectivity-weighted fall velocity and median size) effectively results in the change of the coefficient by a factor $a_{1}$. If the gamma-size distribution is assumed $\left\{N(D)=N_{0} D^{n} \exp \left[-(3.67+n) / D_{0}\right]\right\}$, for the constant particle bulk density $\rho, a_{1}$ can be given as

$$
a_{1}=\Gamma(n+7+B) / \Gamma(n+7)(3.67+n)^{-B},
$$

where $\Gamma$ is the gamma function, and $n$ is the order of this function. Results of modeling $a_{1}$ for changing $\rho$ are presented by Matrosov and Heymsfield (2000).

Matrosov and Heymsfield (2000) used a groundbased multisensor remote sensing method for retrievals of ice cloud parameters developed at the Environmental Technology Laboratory (ETL) to estimate layer mean values of $A$ and $D_{0}$. In these retrievals, mean layer values of particle median size varied in the range from about $25 \mu \mathrm{m}$ to more than $500 \mu \mathrm{m}$, and the values of $A$ generally varied in the range from 250 to 4000 (cgs units). This range of variability in $A$ indicates that a simple assumption of a fixed value for this parameter that is independent on particle size is probably not appropriate.

Analysis of a large amount of experimental data from various field experiments, conducted in different locations and seasons, showed a significant correlation between $A$ and $D_{0}$ (Matrosov and Heymsfield 2000). The best power-law fit representing this correlation is

$$
A=3.5 \times 10^{4} D_{0}^{-0.62},
$$

where $D_{0}$ is in microns and $A$ is in cgs units. The $A$ and $D_{0}$ retrievals used to derive (5) were obtained from combined Doppler radar and IR brightness temperature measurements as outlined by Matrosov (1997). Equation (5) reflects a gradual decrease of $A$ with particle size-a feature that is not readily expressed by any single $V_{Z^{-}}$ $D_{0}$ relation that is based on drag force calculations with 
fixed parameters of mass- and area-dimensional power laws. A tendency for $A$ is obviously present when such calculations are made for parameters at different size intervals (see lines in Fig. 1). Expression (5) is statistically significant with the correlation coefficient (the square root of the variance) being about 0.81 .

Substituting (5) into (4), one can get $V_{Z}-D_{0}$ relations for different assumptions of the PSDs. Symbols in Fig. 1 show these relations for different orders of the assumed gamma-function size distribution, $n$. It has been shown (Kosarev and Mazin 1991) that $n=0$ (i.e., the exponential distribution), $n=1$, or $n=2$ usually satisfactorily describes observed particle size spectra in ice clouds. Though modeling particle size distribution by gamma functions is an idealization, these functions were shown to satisfactorily describe about $80 \%$ of experimental size distributions for particles greater than 20$30 \mu \mathrm{m}$. Smaller particles sometime exhibit a secondary maximum, though their contribution to measured radar parameters is often negligible.

As one can see from symbols in Fig. 1, there is not much sensitivity of the $V_{Z}-D_{0}$ relations to the order of the gamma distribution, especially if $V_{Z}$ is less than about $70-80 \mathrm{~cm} \mathrm{~s}^{-1}$. The variability due to $n$ increases for higher fall velocities. The best polynomial fits for different values of $n$ are also shown in Fig. 1. Since particle fall velocities depend on air density $\rho_{a}$, an altitude-dependent correction needs to be applied to $V_{Z}$ when estimating $D_{0}$ using $V_{Z}-D_{0}$ relations. The correction coefficient is approximately proportional to $\left(\rho_{a} \rho_{\mathrm{ar}}^{-1}\right)^{\epsilon-1}$, where $\rho_{a}$ and $\rho_{\mathrm{ar}}$ are air densities at the measurement and reference (e.g., at the sea surface) levels, respectively, and $\epsilon \approx 0.75$ for larger ice cloud particles (Pruppacher and Klett 1978).

\section{b. Uncertainties of $D_{0}$ estimates}

Uncertainties of the $V_{Z}-D_{0}$ relations (4) are determined by uncertainties of the $B-A$ relation (2), the uncertainties of the $A-D_{0}$ relation (5), and the uncertainty of the coefficient $a_{1}$. However, the variability of the $V_{Z^{-}}$ $D_{0}$ relations due to $a_{1}$ when $n$ changes from 0 to 2 is relatively modest, as can be seen from Fig. 1. When $V_{z}$ is in the range from 25 to $80 \mathrm{~cm} \mathrm{~s}^{-1}$ (i.e., typical values of $V_{z}$ in ice clouds), $D_{0}$ changes by less than about $8 \%$ from its mean value for a given value of $V_{z}$.

Relations (2) and (5) were derived by Matrosov and Heymsfield (2000). The relative standard deviations of the data [i.e., $B$ in (2) and $A$ in (5)], with respect to the best fit curves, were found to be about $6 \%$ and $30 \%$, correspondingly. Such standard deviations of $B$ and $A$ transform into about $28 \%$ and $20 \%$ uncertainties of $D_{0}$ for a given value of the $V_{z}$. These estimates were obtained when assuming the corresponding variabilites (i.e., $6 \%$ and $30 \%$ ) in (4). Note that the uncertainty of (4) due to $B$ variations has two sources, since $B$ is present in (4) not only through the $D_{0}^{B}$ term but also through $a_{1}$ [see (4a)]. If one assumes that individual uncertainty contributions discussed above are independent (i.e., the square of the total standard deviation can be approximated as a sum of squares of individual contributions $\rightarrow \sigma^{2} \approx \Sigma_{i} \sigma_{i}^{2}$, the total uncertainty of $V_{Z}-D_{0}$ relations expressed in the anticipated variability of $D_{0}$ for a given value of $V_{Z}$ will amount to about $35 \%$.

This uncertainty can also be perceived by comparing the $V_{Z}-D_{0}$ relations proposed here with $V_{Z}-D_{0}$ relations derived from data suggested earlier by different authors for some common particle habits. Different lines in Fig. 1 show results of calculations using the expressions for the aerodynamic drag force and mass- and area-dimensional power laws for particle types commonly found in ice clouds. The calculation procedure from the drag force equations was outlined by Mitchell (1996) and Matrosov and Heymsfield (2000). The results of calculations are shown for such common ice cloud particle types as bullet-rosettes, polycrystals, and hexagonal columns, for size intervals as defined by the original authors (Mitchell 1996; Heymsfield and Iaquinta 2000). Though it was assumed in the calculations that the coefficient $A$ and the exponent $B$ were constant for a given particle habit and size interval (as the original authors suggested), the results of these calculations reveal that $A$ and $B$ generally decrease (as seen from the curve behavior in Fig. 1) as a transition is made toward larger particles. Since the variability due to $n$ is rather modest, calculations using Mitchell (1996) and Heymsfield and Iaquinta (2000) data are presented for $n=1$. The $V_{Z}-$ $D_{0}$ relations suggested here (shown by symbols in Fig. 1) account for gradual changes of $A$ and $B$ as characteristic particle size changes in a large dynamic range, and they approximate data from Mitchell (1996) and Heymsfield and Iaquinta (2000) reasonably well, given the expected uncertainty of about $35 \%$.

\section{c. Estimating reflectivity-weighted fall velocity}

The information on $V_{Z}$ needed for size retrievals is extracted from Doppler velocity measurements. In reality, the Doppler velocity, $V_{D}$, measured by the vertically pointed radar, is the sum of the vertical air motion $V_{a}$ and the reflectivity-weighted cloud particle fall velocity $V_{Z}$ :

$$
V_{D}=V_{a}+V_{Z}
$$

For microphysical retrievals, the contribution from $V_{a}$ should be accounted for or, at least, minimized. The vertical air motion contribution can be estimated if collocated measurements from a Doppler wind profiler are available. An example of the use of a 404-MHz profiler to estimate mean air motions beneath and above a cloud was given by Orr and Kropfli (1999). Values of $V_{a}$ inside a cloud can be then interpolated. This approach, though, requires another sensor, which is not often available.

Another approach to minimize the contribution of vertical air motions is to perform time averaging of Doppler velocity measurements. If no strong updrafts 


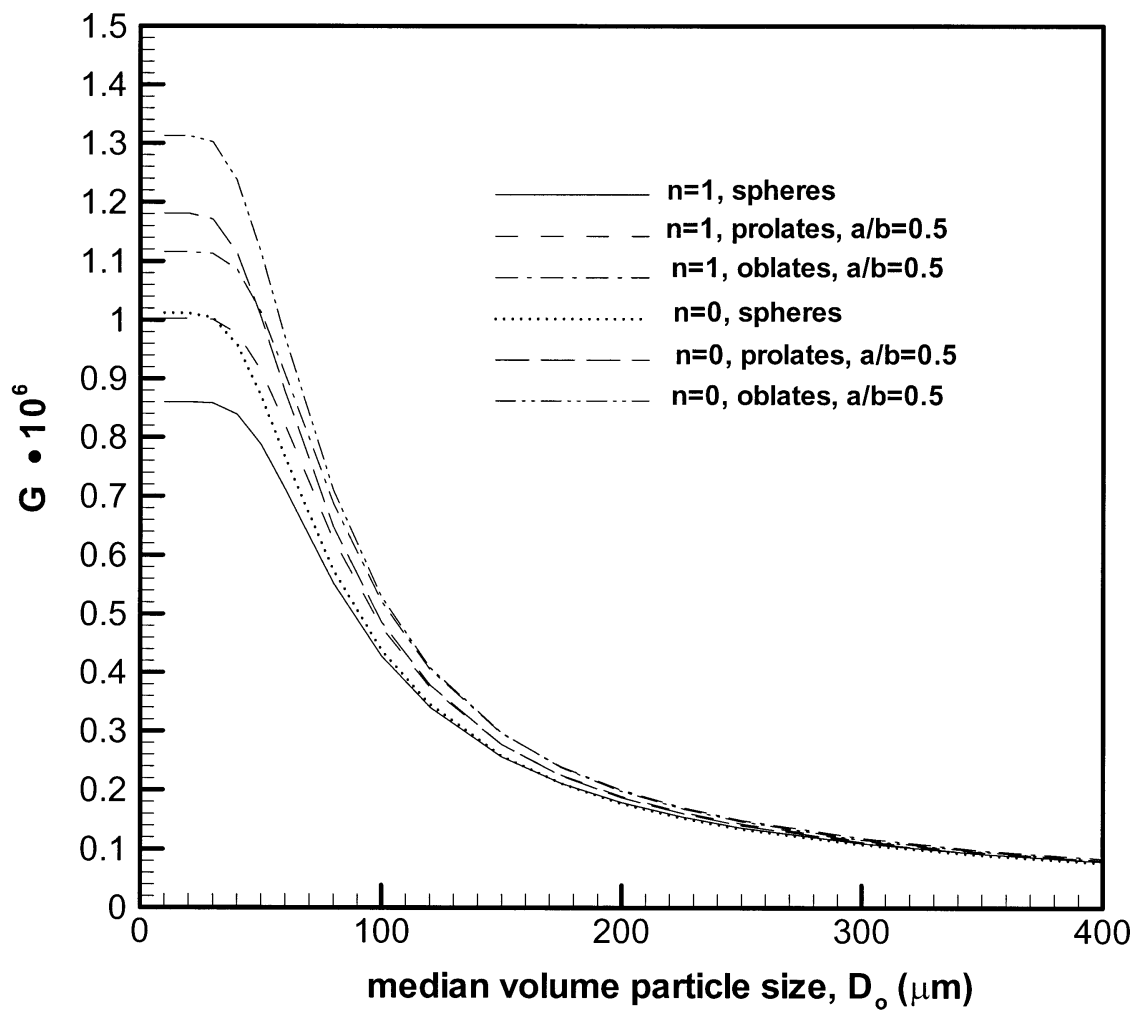

FIG. 2. Coefficient $G$ as a function of $D_{0}$ for different orders of the gamma-function particle size distribution $(n)$ and different particle aspect ratios $(a / b)$.

and/or downdrafts are present, the residual of $V_{a}$ is relatively small. For flat terrain measurements of horizontally extended clouds and time averaging over 20-30min intervals, the residual of $V_{a}$ is usually less than about $6 \mathrm{~cm} \mathrm{~s}^{-1}$ (Matrosov et al. 1995). When a $V_{z}-D_{0}$ relation is fixed, such a residual in vertical air motions can amount to uncertainty in $D_{0}$ of about $8 \%-20 \%$ for typical values of $V_{D}$ observed in ice clouds $(\sim 30-80$ $\mathrm{cm} \mathrm{s}^{-1}$ ). Coupled with the about $35 \%$ uncertainty in the $V_{Z}-D_{0}$ relations, the total uncertainty of $D_{0}$ estimates should be about $36 \%-40 \%$, assuming the independence of different uncertainty contributions.

As a check on the ability of temporal averaging to remove vertical air motions, one can analyze the resulting $\left\langle V_{D}\right\rangle$ and $\left\langle Z_{e}\right\rangle$ cloud measurement fields (the angular brackets mean time averaged values). For the lowest values of $\left\langle Z_{e}\right\rangle$, which usually correspond to small cloud particles, $\left\langle V_{D}\right\rangle$ values should be around zero. The most convenient areas for this check are regions near cloud tops, where particles are usually the smallest. After such averaging, values of $\left\langle V_{D}\right\rangle$ can be used as a proxy of mean reflectivity-weighted particle fall velocities, $V_{Z}$. It should be mentioned, however, that this approach might not work when significant convective activity or large wavelength gravity waves are present. A similar averaging approach was successfully used by Frisch et al. (1995) for estimating fall velocities of drizzle drops, which are comparable in magnitude to fall velocities of large ice cloud particles. In nonconvective cases of stratus observation, they were able to get good estimates of $V_{Z}$ from $\left\langle V_{D}\right\rangle$ with averaging intervals as small as 5 $\min$.

\section{Estimation of cloud ice water content}

When a vertical profile of particle characteristic size $D_{0}$ is determined from the averaged measurements of Doppler velocity (using the $V_{Z}-D_{0}$ relations), the profile of cloud IWC can be retrieved from the equation for the radar reflectivity. A convenient way of expressing this equation is (Atlas et al. 1995)

$$
Z_{e}=G D_{0}^{3} \mathrm{IWC}
$$

where the coefficient $G$ depends on the details of the particle size distribution, particle shape, and, most importantly, on particle bulk density. For liquid water clouds, $G$ varies quite modestly, but for ice clouds its variability is significant, especially for larger particle populations when the bulk density significantly deviates from that of solid ice.

Figure 2 shows the dependence of the coefficient $G$ on particle median size $D_{0}$ for different models of particle shapes (i.e., aspect ratios $a / b$ ) and different orders of the assumed gamma-function size distribution, $n$. The individual ice particle bulk density-size approximation suggested by Locatelli and Hobbs (1974) and 
confirmed by Brown and Francis (1995) was used for calculating $G$ :

$$
\left.\rho\left(\mathrm{g} \mathrm{cm}^{-3}\right) \approx 0.07 D^{-1.1} \quad \text { (for } D>0.1 \mathrm{~mm}\right) .
$$

For $D_{0}$ values less than about $50 \mu \mathrm{m}$, most of the individual particles in the distribution have the solid ice density. The variability of $G$ due to details of the size distribution function and particle shapes is diminishing when particle characteristic size increases. With increasing $D_{0}$, the bulk density becomes a more important component of changes in $G$, and it becomes a dominant factor for $D_{0}>100 \mu \mathrm{m}$. The dependence of $G$ on $D_{0}$ in Fig. 2 represents a proxy of $G$ dependence on $\rho$.

An average dependence of $G$ on $D_{0}$ in Fig. 2 can be approximated as

$$
\begin{array}{ll}
G \approx\left(7.5 \times 10^{-5}\right) D_{0}^{-1.1} & \left(\text { for } D_{0}>50 \mu \mathrm{m}\right), \\
G \approx 10^{-6} & \left(\text { for } D_{0} \leq 50 \mu \mathrm{m}\right)
\end{array}
$$

when $D_{0}$ is in $\mu \mathrm{m}, Z_{e}$ in (7) is in $\mathrm{mm}^{6} \mathrm{~m}^{-3}$, and IWC is in $\mathrm{g} \mathrm{m}^{-3}$. A typical uncertainty of $G$ due to variations of particle shapes and details of the PSD is about $\pm 20 \%$ for smaller values of $D_{0}$ and it diminishes as particles become larger.

A decrease of $G$ when $D_{0}$ increases results in the fact that for a constant value of ice content in a cloud consisting of larger particles, $Z_{e}$ is proportional to $D_{0}^{1.9}$ rather than $D_{0}^{3}$ as it is for constant density particles. IWC, in its turn, is also proportional to $D_{0}^{1.9}$ rather than $D_{0}^{3}$ because of diminishing density. This results in the approximate proportionality of radar reflectivity $Z_{e}$ to the 3.8th moment of the cloud particle size distribution for clouds with larger values of $D_{0}$. Of course, the classical proportionality of reflectivity to the 6th moment of the distribution remains true for PSDs with smaller values of $D_{0}$. The transition in the proportionality of $Z_{e}$ to different moments of the PSD is accounted for in (7) by the gradual decrease of $G$ with increasing $D_{0}$, as shown in Fig. 2.

The same conclusion can also be arrived at when considering the basic equation for the radar reflectivity of an ice cloud. For a given particle bin size in the Rayleigh scattering approximation,

$$
Z_{e}=\sum c_{l} D_{l}^{6}\left(K_{i}^{2} K_{w}^{-2}\right)_{l},
$$

where $D_{l}$ is the particle bin size, $c_{l}$ is the bin concentration, and the summation ( $l$ is the summation index) is with respect to the whole size distribution. In (10) $K_{i}$ is a function of the refractive index of ice $m_{i}$, given by

$$
\begin{aligned}
K_{j}=\left|\left(m_{j}^{2}-1\right)\left(m_{j}^{2}+2\right)^{-1}\right|, \\
\quad(j=w \text { for water and } j=i \text { for ice }) .
\end{aligned}
$$

The function $K_{w}$ is defined as (11) but for the refractive index of water $\left(K_{w}^{2} \approx 0.9\right.$ at $\left.\lambda=8.6 \mathrm{~mm}, t=10^{\circ} \mathrm{C}\right)$, and $K_{i}^{2}$ is approximately proportional to $\rho^{2}$, as shown in Fig. 3 where the experimental data from Rozenberg (1972) are fitted by a quadratic curve. It can be seen from the discussion above that for larger particles $Z_{e}$

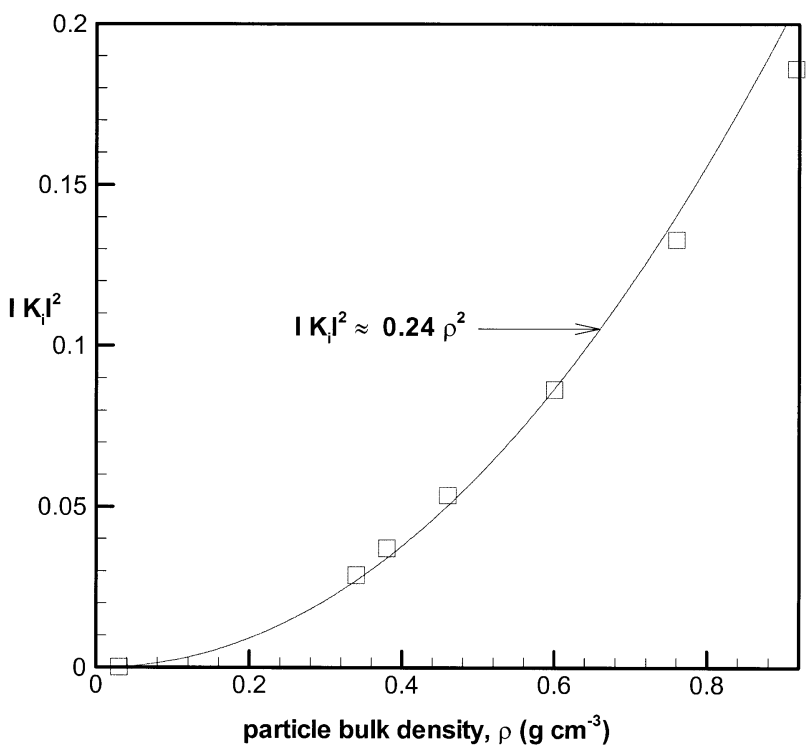

FIG. 3. Relation between $\left|K_{i}\right|^{2}$ and particle bulk density, $\rho$. Symbols show the experimental data.

becomes proportional to the 3.8 th moment of the distribution because of the dependence (8).

It should be noted, however, that here we consider physical particle sizes and not melted ones or the ones recalculated to a constant density. If one considers melted particle diameters, the proportionality of reflectivity to the 6th moment of the distribution remains intact. Considering physical particle sizes has the advantage of the possibility of comparing retrieved particle sizes to in situ measurements taken by standard particle measuring probes.

\section{Uncertainties of IWC estimates}

The parameter $G$ 's proportionality to $D_{0}^{-1.1}$ in (9) reflects the proportionality of the individual particle bulk density to the same power of size in (8). Because of this, IWC is proportional to $\rho^{-1} D_{0}^{-3}$ for a given value of $Z_{e}$, as it can be seen from (7). This, given the assumption about density (8), reduces to the proportionality to $D_{0}^{-1.9}$. Uncertainties of estimates of $D_{0}$ from the Doppler velocity measurements dominate the uncertainties of estimating IWC from (7) for given values of $Z_{e}$ and $D_{0}$. If the uncertainty of $D_{0}$ retrievals is about $36 \%-40 \%$, as estimated above, the result will be factor of about 2 uncertainties of IWC retrievals because of the $D_{0}^{-1.9}$ proportionality. The influence of the density assumption might somewhat change the exponent, which is 1.9 in our current estimates. It could result in some diminishing of IWC uncertainties due to $D_{0}$ uncertainties if the density decreases with increasing particle size at a higher rate. The appropriateness of the assumption (8) is illustrated in the next section (Fig. 7), when comparing radar reflectivity values measured by the radar and calculated from aircraft in situ samples. 
The uncertainties of $D_{0}$ estimates from Doppler velocity measurements play a dominant role in uncertainties of IWC estimates using the suggested approach. The contribution from a typical error of $Z_{e}$ measurements (about $1 \mathrm{~dB}$ ) is much smaller than contributions from the typical uncertainties of $D_{0}$. Uncertainties in $G$ due to variabilities in $n$ and particle shapes contribute to IWC retrieval errors to a much smaller extent than do uncertainties in $D_{0}$ estimates (especially for the characteristic sizes corresponding to $V_{Z}>25 \mathrm{~cm} \mathrm{~s}^{-1}$ ).

In spite of the relatively large uncertainties of IWC estimates, the use of the suggested approach generally should present an improvement over reflectivity-onlybased approaches, that is, IWC- $Z_{e}$ empirical regressions. These regressions, even when tuned for particular observational cases, were found to give larger uncertainties, with corresponding relative standard deviations often exceeding 100\% (Matrosov 1997). Note also that a factor of about 2 uncertainty is typical for inferring IWC from in situ samples.

The suggested procedure for retrieving ice cloud microphysical parameters from vertically pointed Doppler radar measurements can be summarized as follows. The Doppler velocity measurements are averaged over a certain time interval (typically 20-30 $\mathrm{min}$ ) to ensure that a residual vertical air motion contribution is small compared to cloud particle reflectivity-weighted fall velocities. The results of averaging are used to estimate vertical profiles of cloud particle median sizes from $V_{Z}-D_{0}$ relations. The estimated vertical profiles of $D_{0}$ and the measured profiles of $Z_{e}$ (which are also averaged in time to match the time resolution of $D_{0}$ estimates) are then used to calculate vertical profiles of IWC from (7).

The use of time averages of reflectivity and Doppler velocity measurements in the proposed remote sensing method results in effective averaging of the retrieved values of $D_{0}$ and IWC. Such averaging is straightforward and unbiased if $V_{Z}-D_{0}$ and $Z_{e}$-IWC relations are linear. It can be seen from Fig. 1 that the suggested $V_{Z}$ $D_{0}$ relations deviate from a linear behavior relatively insignificantly if velocities are less than about 50-60 $\mathrm{cm} \mathrm{s}^{-1}$. The $Z_{e}-$ IWC relations are strictly linear for a given value of $D_{0}$. This means that retrieval results will represent simple time averages of microphysical parameters over the averaging time if Doppler velocities are not too high. However, even for high Doppler velocities the averaging results will be generally unbiased if the variability in $V_{D}$ is fairly small, so the velocity-characteristic size relations can be considered quasi-linear over the interval of velocity changes. For clouds with high Doppler velocities that also exhibit a high variability of $V_{D}$, retrieved values of microphysical parameters will represent some effective temporal averages that might deviate from simple arithmetic averages.

\section{Experimental examples}

The First International Satellite Cloud Climatology Project (ISCCP) Regional Experiment (FIRE) Arctic
Cloud Experiment (ACE) was conducted in the Arctic Ocean north of Alaska during April-July 1998 (Curry et al. 2000). FIRE ACE was a part of a year-long Surface Heat Budget of the Arctic (SHEBA) field program. Different instruments were deployed on board a Canadian icebreaker that was drifting in the Arctic Ocean. The remote sensors available for microphysical retrievals included the vertically pointed Millimeter Wavelength Cloud Radar (MMCR), the Atmospheric Emitted Radiance Interferometer (AERI), the Depolarization and Backscatter Unattended Lidar (DABUL), and the twochannel (31.4 and $23.8 \mathrm{GHz}$ ) microwave radiometer. Brief descriptions of these sensors can be found in Curry et al. (2000). In this section, microphysical retrievals for two FIRE ACE cloud cases that had aircraft in situ support are presented. One of these cases (28-29 April $1998)$ represents a pure-ice-phase cloud, and the other (21-22 April 1998) represents a predominantly icephase cloud with thin liquid layers embedded in it.

\section{a. The observational case of 28-29 April 1998}

An ice cloud was observed over the SHEBA camp during a time period of more than $16 \mathrm{~h}$. Microwave radiometer measurements of integrated liquid water and depolarization data from DABUL indicated no presence of liquid phase in this cloud. Figure 4 shows the timeheight cross sections of the (a) radar reflectivity and (b) Doppler velocity measured by MMCR. The reflectivity and Doppler velocity measurements were averaged in 20-min intervals, as described above.

It should be mentioned that since MMCR was deployed on board the ship, the perfectly vertical alignment of the radar beam was not possible due to ship movements. This could cause contaminations of Doppler velocity measurements due to a "leak" from the horizontal winds, $V_{h}$. If the radar beam is inclined from the vertical direction in the crosswind direction, this contamination is absent. The magnitude of this contamination is maximal when the radar beam deviation occurs along the wind direction. This maximum contribution of horizontal winds to Doppler velocity measurements, $\boldsymbol{v}_{h}^{(m)}$, in this case can reach

$$
v_{h}^{(m)}=V_{h} \sin \beta,
$$

where $\beta$ is the radar beam deviation angle from the vertical direction.

During the observational event of 28-29 April 1998, $\beta$ was about $0.7^{\circ}$, and the radiosonde soundings indicated that horizontal winds at cloud altitudes did not exceed about $9 \mathrm{~m} \mathrm{~s}^{-1}$. This will contribute to a maximum possible contamination $v_{h}^{(m)}$ of less than $10 \mathrm{~cm} \mathrm{~s}^{-1}$. The real contamination was significantly less than this estimate of the maximum possible contamination, since the radar beam did not deviate significantly from vertical along the wind direction. This justifies ignoring the horizontal wind component for this observational case, although each case should be judged independently based 
a)

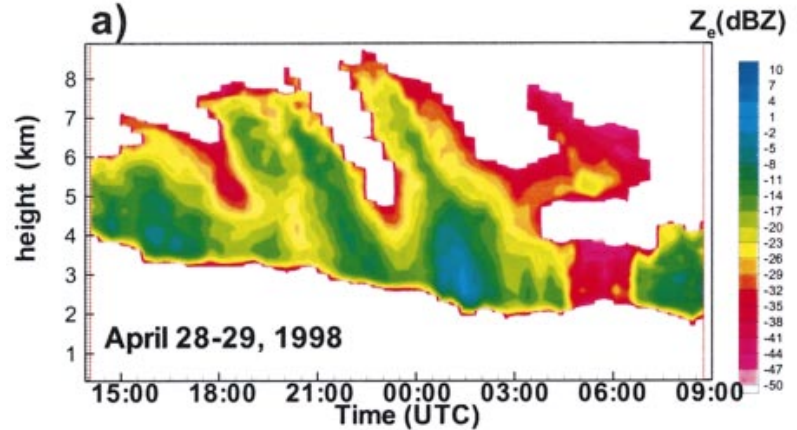

c)

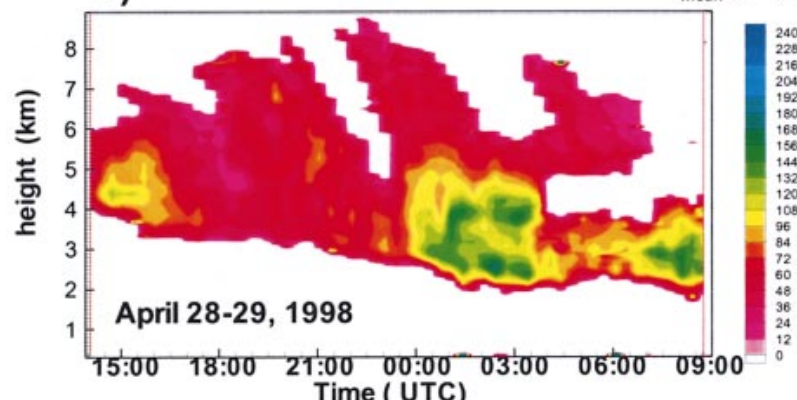

e)

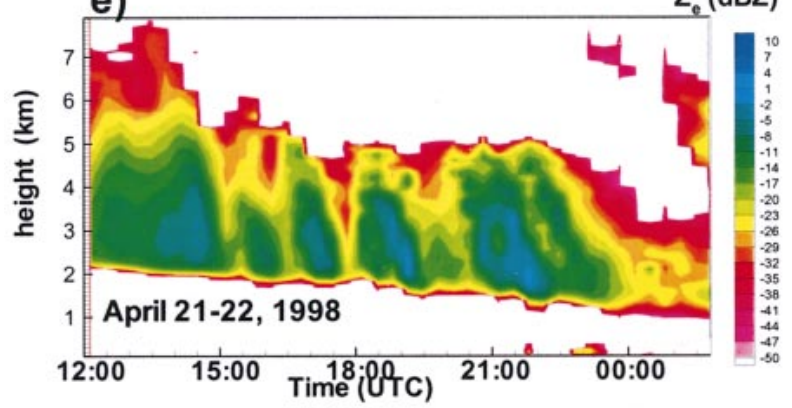

g)

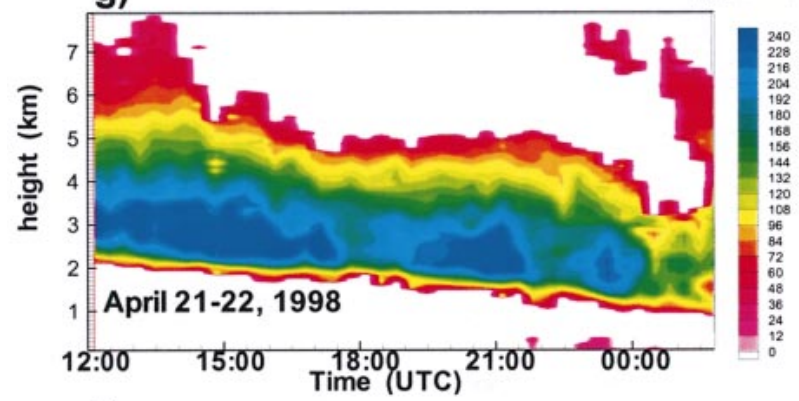

i)

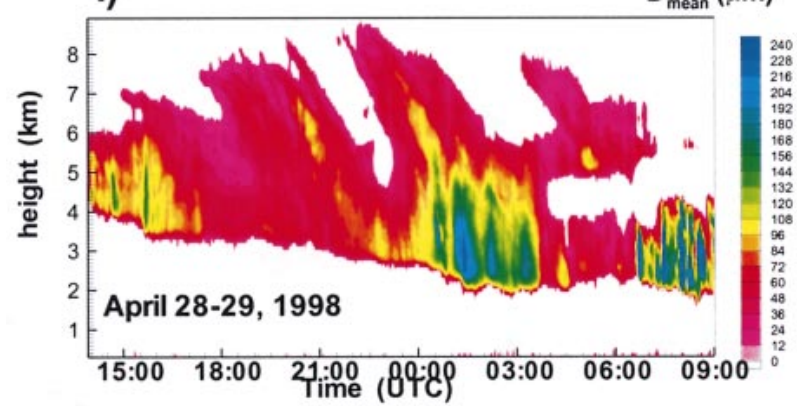

b)

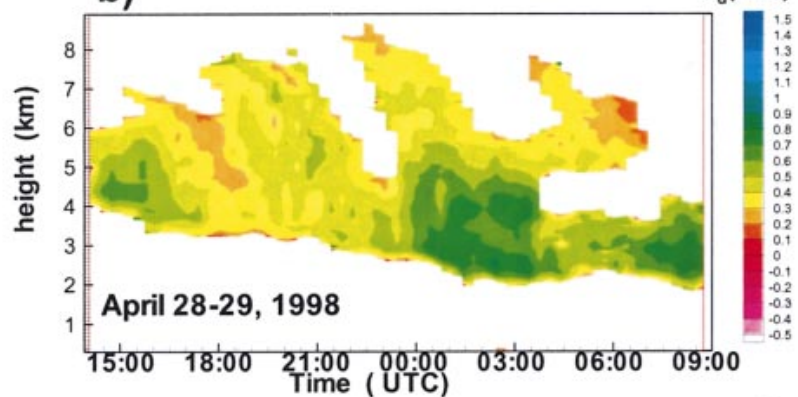

d)

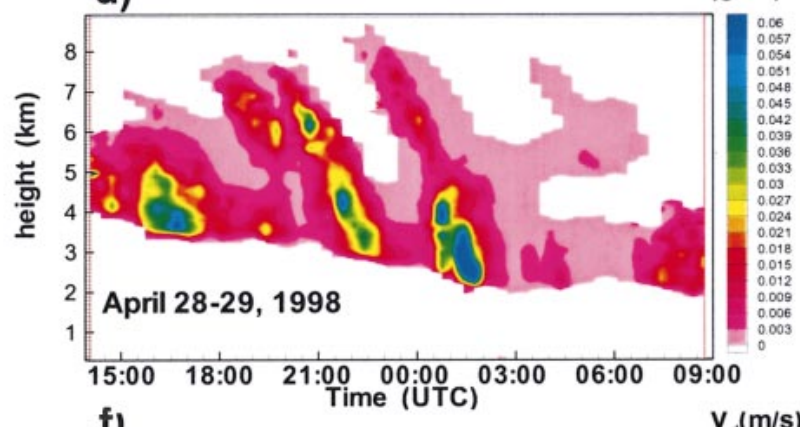

f)

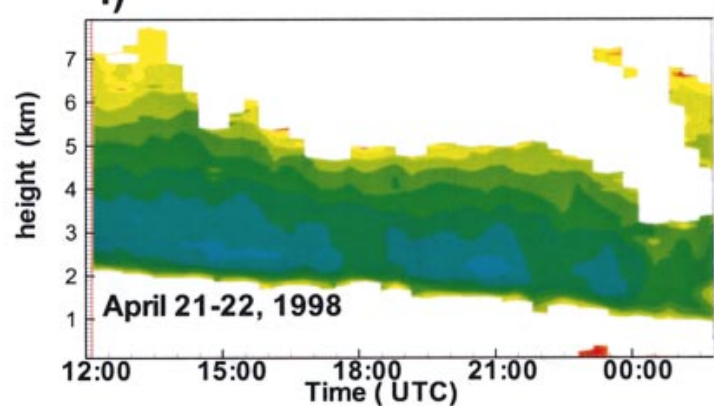

$(\mathrm{m} / \mathrm{s})$

h)

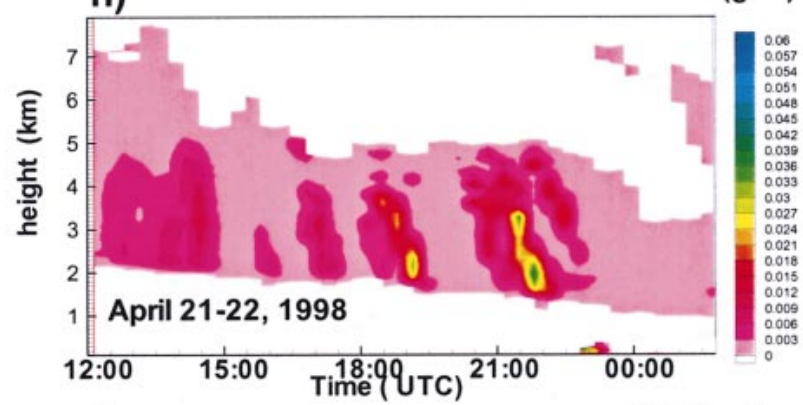

j)

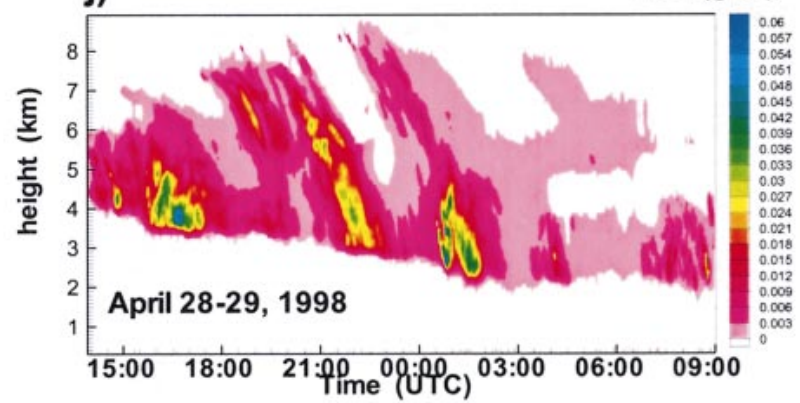




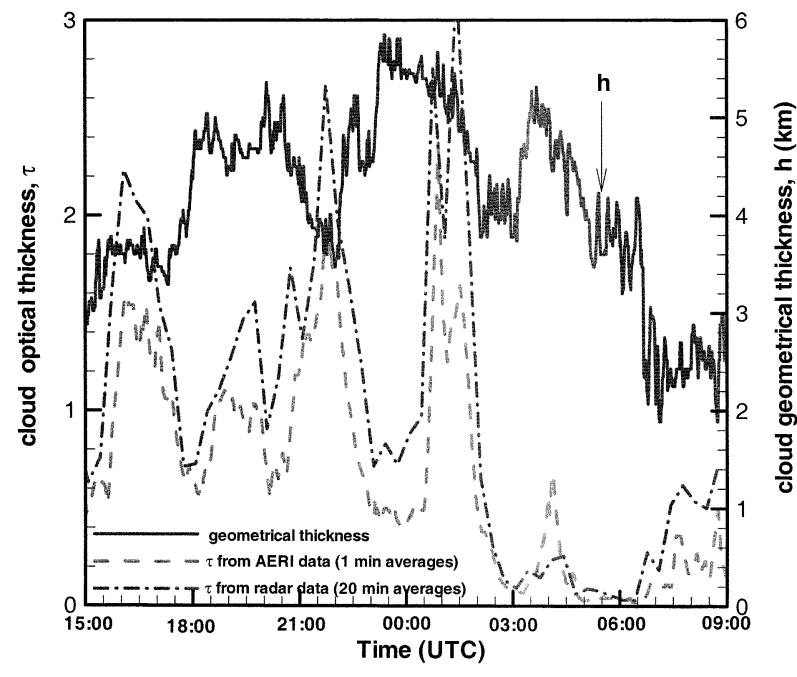

FIG. 5. Time series of the cloud geometrical and IR optical thicknesses for the observational case of 28-29 Apr 1998.

on available data on horizontal winds and the deviation of the radar beam from the vertical direction.

Twenty-minute averaging of Doppler velocities resulted in the smallest values of $\left\langle V_{D}\right\rangle$ being just slightly above $0 \mathrm{~cm} \mathrm{~s}^{-1}$ near the cloud boundaries (see Fig. 4b, where downward velocities are positive), which is another indication that there were no significant contributions from air motions. Estimates of the cloud optical thickness, $\tau$, from the ground-based radiometric (AERI) measurements showed that $\tau$ was varying between 0.5 and 2.5 (as depicted in Fig. 5), except for most of the time period after 0300 UTC, when it was generally less than 0.5 . Thus, this cloud was radiatively important for most of the period of its existence. Though it was geometrically very thick, it remained optically semitransparent for the whole $16-\mathrm{h}$ period of observations. This cloud began to precipitate shortly after 0900 UTC on 29 April 1998.

Figures $4 \mathrm{c}$ and $4 \mathrm{~d}$ show the microphysical retrieval results for this observational case from the MMCR reflectivity and Doppler velocity measurements. Vertical profiles of cloud particle characteristic sizes (Fig. 4c) are given in terms of mean sizes $D_{\text {mean }}$ rather than median volume sizes $D_{0}$ for more convenient comparisons with in situ measurements $\left[D_{\text {mean }} \approx D_{0}(n+1)(n+3.67)^{-1}\right]$. During the size retrievals, it was assumed that the cloud particle size distribution is exponential in shape.

As the retrieval results show, the mean particle sizes $D_{\text {mean }}$ are generally less than about 80-100 $\mu \mathrm{m}$ except for the cells in the lower part of the cloud between 0000 and 0300 UTC and after 0600 UTC. IWC values for this cloud were also mostly small, except for three fall streaks, as shown in Fig. 4d. The lowest values of IWC (IWC $<2 \mathrm{mg} \mathrm{m}^{-3}$ ) around 0300 and 0600 UTC correspond to the smallest values of optical thickness $\tau$ when the cloud was practically transparent. The maximum optical thicknesses $\tau$ (see Fig. 5) in this cloud were observed at the time periods of the fall streaks, indicating that larger values of $\tau$ were primarily associated with increases in cloud IWC.

\section{b. The observational case of 21-22 April 1998}

A geometrically thick cloud was observed over the SHEBA camp on 21-22 April 1998. Twenty-minute time averages of MMCR radar reflectivities and Doppler velocities are shown in Figs. $4 \mathrm{e}$ and $4 \mathrm{f}$. Though it was a predominantly ice-phase cloud, according to the DABUL depolarization measurements, a very thin layer of liquid stratus cloud was present during most of the observation time in the lower $100 \mathrm{~m}$. At times, the lidar signals were completely attenuated by this layer. This thin stratus cloud is not seen in Figs. 4e and 4f, except for a little speck around 2300 UTC, because the first meaningful radar range gate was at $105 \mathrm{~m}$, which was generally higher than the stratus cloud. DABUL depolarization data also indicated that a very thin water layer could also be present near the ice cloud base for a short time at around 1900 UTC. This layer, however, did not contribute much in radar measurements, since drop sizes were significantly smaller than ice particle sizes.

The deviation of the radar beam from vertical during this case was about $0.9^{\circ}$, and maximum horizontal winds at cloud altitude did not exceed $7 \mathrm{~m} \mathrm{~s}^{-1}$, so the maximum possible contamination of the Doppler velocity measurements by the horizontal winds was about $10 \mathrm{~cm}$ $\mathrm{s}^{-1}$. As in the case of 28-29 April 1998, the actual contaminations were much smaller, since the radar beam deviations from vertical were not in the plane of wind direction. Overall, these contaminations were much less than the 20-min averages of Doppler velocities shown in Fig. 4f. Very small Doppler velocities near the cloud top and in the region of the stratus cloud (around 2300 UTC) represent an independent verification that the overall contributions of air motions to averaged Doppler velocities in the main body of the cloud were negligible. These velocities, however, were higher than typical values usually observed in nonprecipitating ice clouds.

Overall, the radar reflectivities observed during the case of 21-22 April were comparable to those from the

$\leftarrow$

FIG. 4. Time-height cross sections of observed $\left(Z_{e}\right.$ and $\left.V_{d}\right)$ and retrieved ( $D_{\text {mean }}$ and IWC) parameters for the observational case of (a), (b), (c), (d), (i), (j) 28-29 Apr 1998 and (e), (f), (g), (h) 21-22 Apr 1998. The data in (a)-(h) are averaged in 20-min intervals and represent the input and output information for the Doppler velocity-reflectivity method. The data in (i) and (j) show the results of retrievals using the radar-radiometer "tuned" regression method with 1-min temporal resolution. 
case of 28-29 April (Figs. 4a,e). The Doppler velocities for the latter case, however, were significantly lower (Figs. 4b,f). This resulted in generally larger retrieved mean particle sizes for the case of 21-22 April compared to 28-29 April. Cloud IWC values for both these observational cases were rather small (Figs. 4d,h), except for a few fall streaks.

\section{Comparisons with other retrieval methods and in situ measurements}

\section{a. Comparisons with radar-radiometer retrieval method}

The cloud microphysical parameters retrieved from 20-min averages of radar reflectivity and Doppler velocity measurements using the procedure outlined in sections 2 and 3 were compared with the results of retrievals from the "tuned" regression method suggested by Matrosov (1999). The tuned regression method uses measurements of the radar reflectivity profiles and estimates of the cloud absorption optical thickness $\tau_{a}$ to retrieve the vertical profiles of the same ice cloud microphysical parameters (i.e., IWC and the cloud particle characteristic size). For estimations of cloud IR absorption optical thickness in this method, IR window $(\lambda \sim 11 \mu \mathrm{m})$ brightness temperatures of downwelling cloud radiation from AERI coupled with water vapor estimates from the microwave radiometer (for accounting for the atmospheric transmission and background radiation) and the cloud boundary information from the radar were used. A reasonable assumption for the extinction optical thickness of ice clouds consisting of relatively large particles is $\tau \approx 2 \tau_{a}$ (Matrosov et al. 1998).

The tuned regression approach has been used to process FIRE ACE cloud data (Shupe et al. 2001). It proved to be rather robust. The main drawback of this method was the limitation of its applicability to pure-ice-phase clouds only, which were unobstructed by layers of liquid clouds. It turned out to be a relatively major limitation, since only about $10 \%$ of all cloud observations could satisfy these conditions during the FIRE ACE period. The Doppler velocity-reflectivity method suggested here does not have these limitations, and thus has a significantly greater scope of applicability.

The observational case of 28-29 April 1998 provided a convenient opportunity to compare retrieval results for both remote sensing methods. Figures $4 \mathrm{i}$ and $4 \mathrm{j}$ show the time-height cross sections of the mean particle size $D_{\text {mean }}$ and IWC obtained with the radar-radiometer tuned regression approach. The time resolution of these retrievals $(\sim 1 \mathrm{~min})$ is much finer than that for the Doppler velocity-reflectivity method shown in Figs. 4c and 4d, respectively. Aside from the differences in time resolutions, the microphysical retrieval results are pretty similar for both methods. An assumption of quasi-spherical particles was made for the retrievals. This assump- tion is usually acceptable for irregular particles, which were observed in this case.

In order to compare microphysical retrieval results quantitatively, the radar-radiometer tuned regression method time resolution was degraded to $20 \mathrm{~min}$ to match the time resolution of the Doppler velocity-reflectivity method. Comparisons showed that for the 28-29 April case the Doppler velocity-reflectivity method estimates of $D_{\text {mean }}$ and IWC were, on average, biased just $5 \%$ and $21 \%$ higher than those from the tuned regression method. The corresponding relative standard deviations (RSD) between the two methods were about 27\% (for $\left.D_{\text {mean }}\right)$ and $38 \%$ (for IWC). These values are well within the expected retrieval uncertainties. The bias and RSD between two datasets ( $x$ and $y$ ) were defined as

$$
\begin{aligned}
(\mathrm{RSD})^{2} & =\frac{4}{N} \sum_{i}^{N} \frac{\left(x_{i}-y_{i}\right)^{2}}{\left(x_{i}+y_{i}\right)^{2}} \\
\text { bias } & =\frac{2}{N} \sum_{i}^{N} \frac{\left(x_{i}-y_{i}\right)}{\left(x_{i}+y_{i}\right)} .
\end{aligned}
$$

The good agreement between these two microphysical remote sensing methods is quite remarkable and encouraging, given that these methods use significantly independent input information (especially for the particle size retrievals). The quantitative comparisons between the tuned regression and Doppler velocity-reflectivity methods were not available for the observational case of 21-22 April 1998 because the liquid layers during this case prevented the use of the radar-radiometer tuned regression method.

\section{b. Comparisons with in situ data for the case of 28- 29 April 1998}

The Canadian Atmospheric Service CV-580 instrumented research aircraft was part of the FIRE ACE field experiment. There were four flights over the SHEBA camp, two of them conducted during the ice cloud observational cases considered here. During the other two flights, mostly liquid clouds were present over the site, so they were not suited for ice cloud microphysical retrieval verifications. Due to long flight distances to the SHEBA camp, the aircraft time over the instrumented ship was mostly limited to one spiral descent from the cloud top to the cloud base for each observational case. During these descents, the horizontal deviations of the aircraft from the shipboard remote sensors generally did not exceed $3 \mathrm{~km}$.

Figure 6 shows comparisons of microphysical retrieval results with values of cloud parameters calculated from two-dimensional cloud (2DC) particle measuring system (PMS) probes for the observational case of 2829 April 1998. The great majority of cloud particles were irregular spatial aggregates with approximately equal dimensions along both optical axes of the PMS probe. The spiral descent of the aircraft from around 7 $\mathrm{km}$ above ground level (AGL) near the cloud top to the 
a)

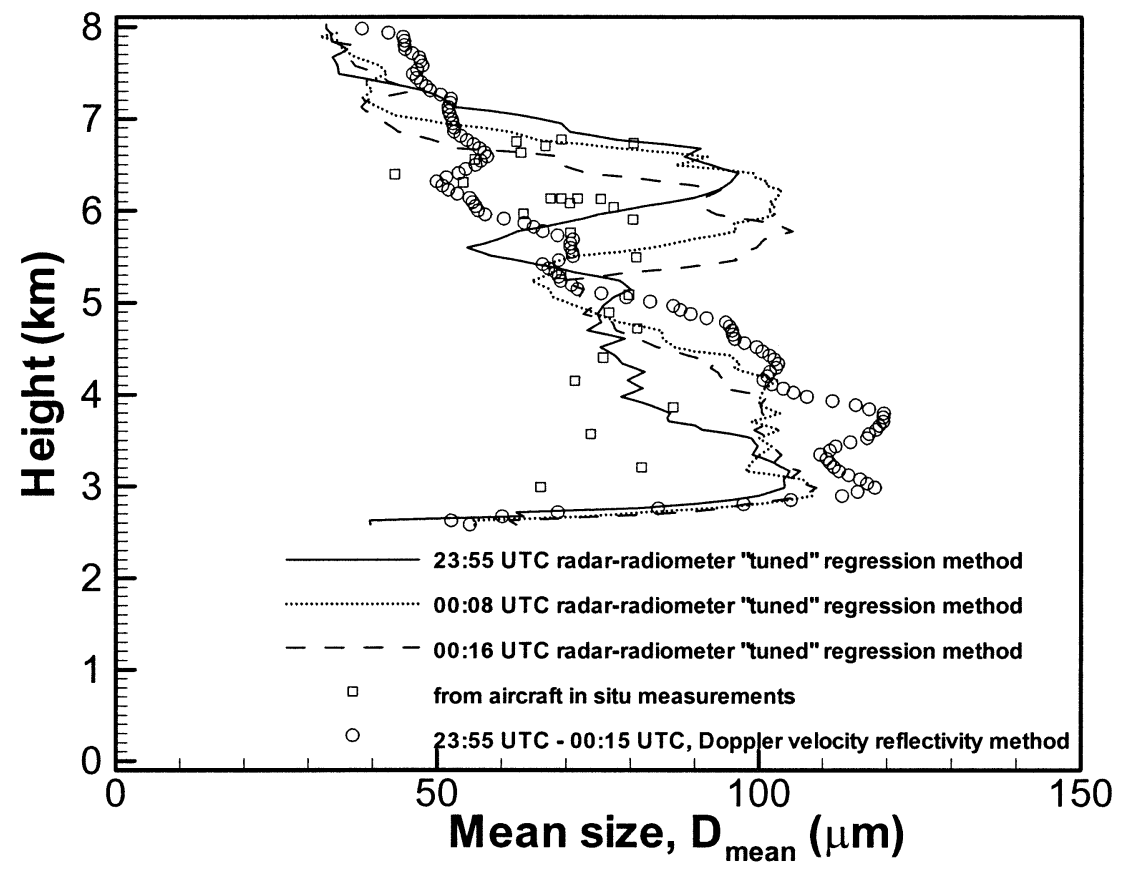

b)

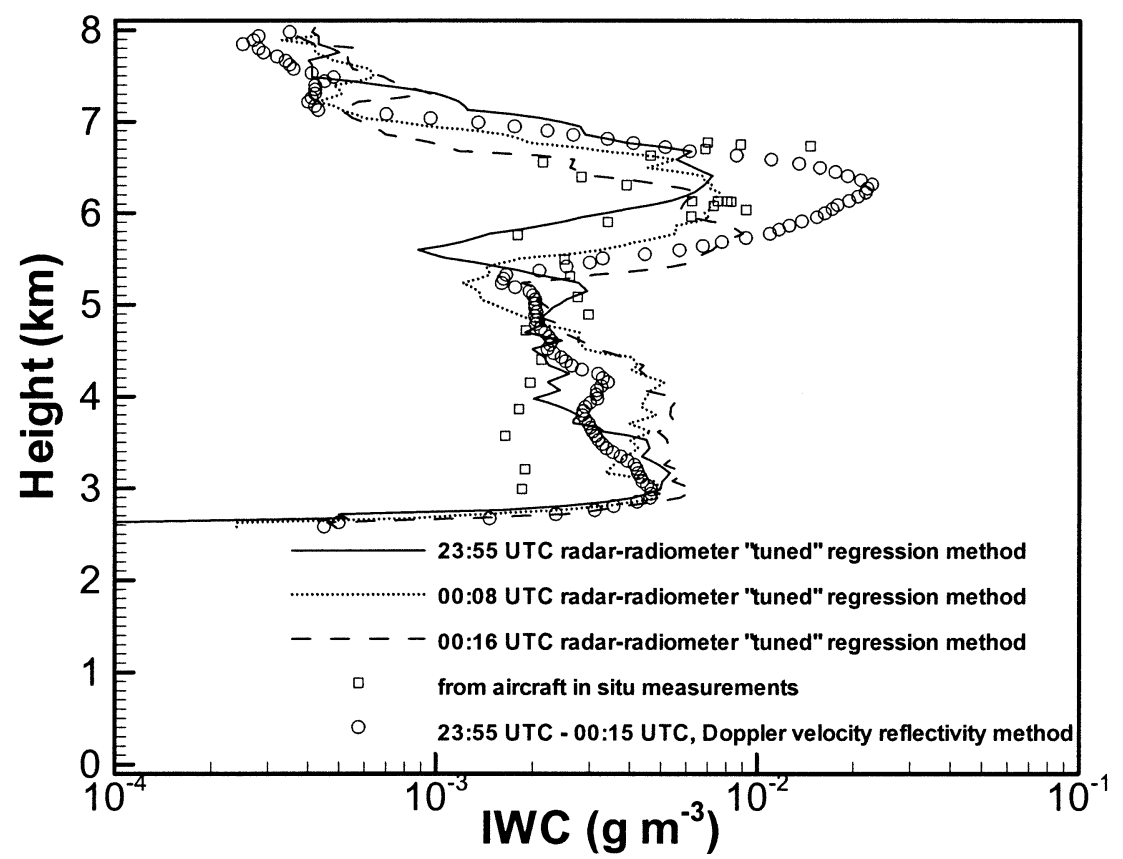

FIG. 6. Comparisons of in situ and remote estimates of (a) $D_{\text {mean }}$ and (b) IWC for the observational case of 28-29 Apr 1998. Data correspond to the aircraft descent over the radar.

vicinity of the cloud base at about $3 \mathrm{~km}$ AGL took about $20 \mathrm{~min}$, from about 2355 UTC 28 April to 0015 UTC 29 April 1998. Circles in Fig. 6 show the results of the retrievals using the Doppler velocity-reflectivity meth- od for the 20-min time interval of the aircraft descent. For comparison, the retrievals obtained from the radarradiometer tuned regression method are also depicted in this figure. The corresponding 1-min resolution pro- 


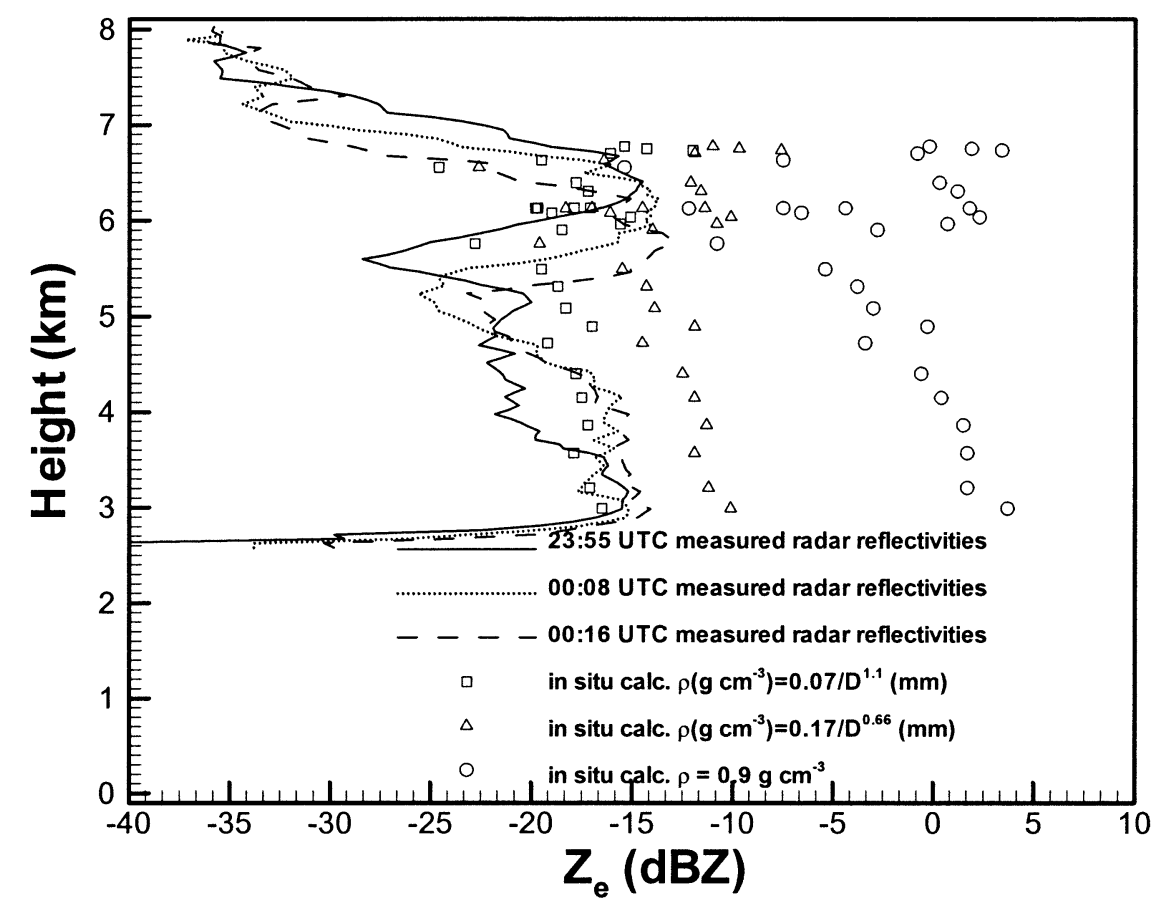

FIG. 7. Comparisons of measured values and in situ estimates of $Z_{e}$ for different assumption for $\rho$. Data correspond to the aircraft descent over the radar.

files from this method are shown for the beginning, middle, and end of the aircraft descent.

Both remote sensing methods and in situ measurements exhibit a profound maximum of IWC near $6 \mathrm{~km}$ AGL and a very low variability of IWC with height in the lower part of the cloud. The best agreement is reached for the middle part of the cloud between 4 and $5.5 \mathrm{~km}$. The relative standard deviation of remotely measured data from in situ estimates was about $50 \%$ for the radar-radiometer tuned regression method and 55\% for the Doppler velocity-reflectivity method. The average bias was about $25 \%-30 \%$, with remote sensing methods providing generally higher values of IWC, especially in the lower part of the cloud. Such discrepancies are well within the uncertainties of both remote sensing approaches as well as within the uncertainties of in situ estimates of IWC in which the bulk densityparticle size relation (8) was assumed.

The relative standard deviations between remote and in situ estimates of mean particle size $D_{\text {mean }}$ are about 25\% (see Fig. 6a). Here, as in the case with cloud IWC, the agreement between remotely measured and in situ data is the best in the middle part of the cloud. In situ 2DC measurements indicated populations of smaller particles compared to remote sensing methods in the lower part of the cloud. There, however, total particle concentrations were small, which might have affected the statistics of in situ sampling.

The in situ cloud particle size distributions can be used to calculate a vertical profile of radar reflectivity using (10). Since such calculations depend on particle density assumptions, because $K_{i}^{2} \sim \rho^{2}$, comparison of the calculated reflectivity profile with profiles measured by the radar allows an independent check of such assumptions. Figure 7 shows the results of the comparisons where the measured profiles of $Z_{e}$ are shown for the times of the beginning, the middle, and the end of the aircraft descent. Different symbols in Fig. 7 correspond to three different assumptions about particle bulk density that were used for calculations.

It can be seen that the assumption of the solid ice bulk density independent of particle size $(\rho=0.9 \mathrm{~g}$ $\mathrm{cm}^{-3}$ ) greatly overestimates calculated reflectivites compared to the real measurements. The corresponding overestimation is about $15-20 \mathrm{~dB}$. In contrast to that, the reflectivity values calculated using the assumption (8) are generally within a couple of decibels from measured reflectivities, and they follow the shape of the measured profiles. This agreement indicates that the assumption (8) is an appropriate one (at least for the considered dataset). As an illustration, the results of calculations are also shown for the density assumption,

$$
\rho\left(\mathrm{g} \mathrm{cm}^{-3}\right) \approx 0.175 D^{-0.66} \quad(\text { for } D>0.1 \mathrm{~mm})
$$

which was discussed by Liu and Illingworth (2000) in addition to the assumption (8). As one can see from Fig. 7 , the reflectivities calculated for in situ particle spectra using (15) exceed the measured ones by about $5 \mathrm{~dB}$ on average. 


\section{c. Comparisons with in situ data for the case of 21- 22 April 1998}

Figure 8 shows comparisons of in situ data with results of the microphysical retrievals from the Doppler velocity-reflectivity method (Figs. 8a,b) and with measurements of $Z_{e}$ (Fig. 8c). The descent time of the aircraft above the SHEBA site from 4 to about $1.4 \mathrm{~km}$ AGL took about $20 \mathrm{~min}$. The particle concentrations during this observational case were small, so for sensible statistics of particle sampling, long time-averaging intervals (of the order of $\sim 10 \mathrm{~min}$ ) were required. The in situ estimates of $D_{\text {mean }}$, IWC, and $Z_{e}$ are shown by arrows in Fig. 8 for two 10-min time intervals: 23202330 and 2330-2340 UTC. The vertical lengths of these arrows show the aircraft altitude intervals during the averaging time of in situ data. As before, the bulk density assumption (8) was used to estimate IWC and $Z_{c}$ from in situ measurements of particle size distributions. The remote sensing results in Fig. 8 are represented by the retrieved profiles of $D_{\text {mean }}$ (Fig. 8a) and IWC (Fig. 8 b) for two 20-min time intervals centered at 2330 and 2350 UTC. Figure $8 \mathrm{c}$ depicts the measured vertical profiles of radar reflectivity for these time intervals. Retrievals from the radar-radiometer tuned regression approach were not available for this case because of the presence of the low-level liquid water cloud.

Due to a rather crude spatial averaging of in situ data, the quantitative comparisons like those done for the case of 28-29 April were not performed for this observational case. However, as it can be seen from Fig. 8, the agreement between remote and in situ estimates of cloud parameters is very reasonable for the lower part of the cloud where the good agreement is also present between radar reflectivities measured by the radar and $Z_{e}$ values estimated from the particle in situ spectra. In the upper parts of the cloud, retrieved microphysical parameters were somewhat smaller than their estimates from in situ data. A similar disagreement, however, is present also between measured and in situ values of $Z_{e}$, which might be explained by some overestimation of particle concentrations due to inadequate statistics of in situ data.

\section{d. Comparisons of radar- and radiometer-derived optical thicknesses}

Optical thickness $\tau$ (i.e., the vertical integral of the extinction coefficient) is a very important optical parameter that influences cloud radiative properties. Many multisensor ice cloud retrieval methods use $\tau$ data (e.g., Matrosov 1997; Mace et al. 1998). In a manner similar to IWC retrievals suggested in section 3 , estimates of cloud extinction coefficients from radar-only data can be performed if an assumption is made about a correspondence between particle size, mass, and cross-sectional area. A comparison of the optical thicknesses $\tau$ estimated from radiometric measurements with estimates of $\tau$ calculated from results of radar-only data using the approach suggested here would be an independent consistency check of this remote sensing approach. The pure-ice cloud case of 28-29 April 1998 offers such an opportunity.

Since the ice cloud extinction coefficient $\alpha$ is proportional to the particle cross-sectional area, in a manner similar to (7), the radar reflectivity can be expressed as

$$
Z_{e}=X D_{0}^{4} \alpha,
$$

Using the density assumption (8) and the size $(D)$-mass $(m)$-cross-sectional area $\left(A_{c}\right)$ relation for ice cloud particles suggested recently by Heymsfield et al. (2002),

$$
m A_{c}^{-1} \approx 0.023 D^{0.59} \quad \text { (cgs units) }
$$

one can make calculations of the coefficient $X$ [analogous to calculations of the coefficient $G$ in (7)].

Figure 9 shows the dependence of the coefficient $X$ on particle median size $D_{0}$ for different orders of the gamma-function size distributions, $n$. Obtaining $X$ from (16) involved calculations of $Z_{e}$ and $\alpha$ [using (17), (8) and assuming that the extinction efficiency is 2 ] as functions of $D_{0}$. As it can be seen from Fig. 9, the variability of $X$ due to $n$ is not very significant. We also neglect the particle shape dependence of $X$ since (8) and (17) are not explicitly shape dependent. The best power-law fit for $X$ is

$$
\begin{array}{ll}
X \approx 2.2 \times 10^{-4} D_{0}^{-1.6} & \left(D_{0}>36 \mu \mathrm{m}\right) \\
X \approx 7 \times 10^{-7} & \left(D_{0} \leq 36 \mu \mathrm{m}\right),
\end{array}
$$

where $D_{0}$ is in $\mu \mathrm{m}, Z_{e}$ in is in $\mathrm{mm}^{6} \mathrm{~m}^{-3}$, and $\alpha$ is in $\mathrm{m}^{-1}$.

Equations (16) and (18) can be used to estimate $\alpha$ from $Z_{e}$ when the information on $D_{0}$ is retrieved from Doppler radar measurements, as discussed in section 2. Integrating vertical profiles of $\alpha$ yields visible optical thickness, $\tau$. Results of radar retrievals of $\tau$ are shown in Fig. 5, along with $\tau$ obtained from radiometric measurements.

Uncertainties of $\alpha$ estimates from radar measurements should be greater than those for IWC since $\alpha \propto$ $Z_{e} D_{0}^{-2.4}$ and IWC $\propto Z_{e} D_{0}^{-1.9}$, though some of these uncertainties could be reduced by the vertical integration of $\alpha$ when calculating optical thickness. The overall agreement between $\tau$ estimates from radar and radiometric measurements is well within the retrieval uncertainties. It should be mentioned, however, that the optical thickness comparisons are presented here as a consistency check for the appropriateness of the presented microphysical retrieval approach, and it is not an intention of this paper to provide a comprehensive analysis of possibilities for measurements of ice cloud optical properties using radar-only data.

\section{Conclusions}

Efficient retrievals of ice cloud microphysical parameters from the ground-based remote sensing measure- 

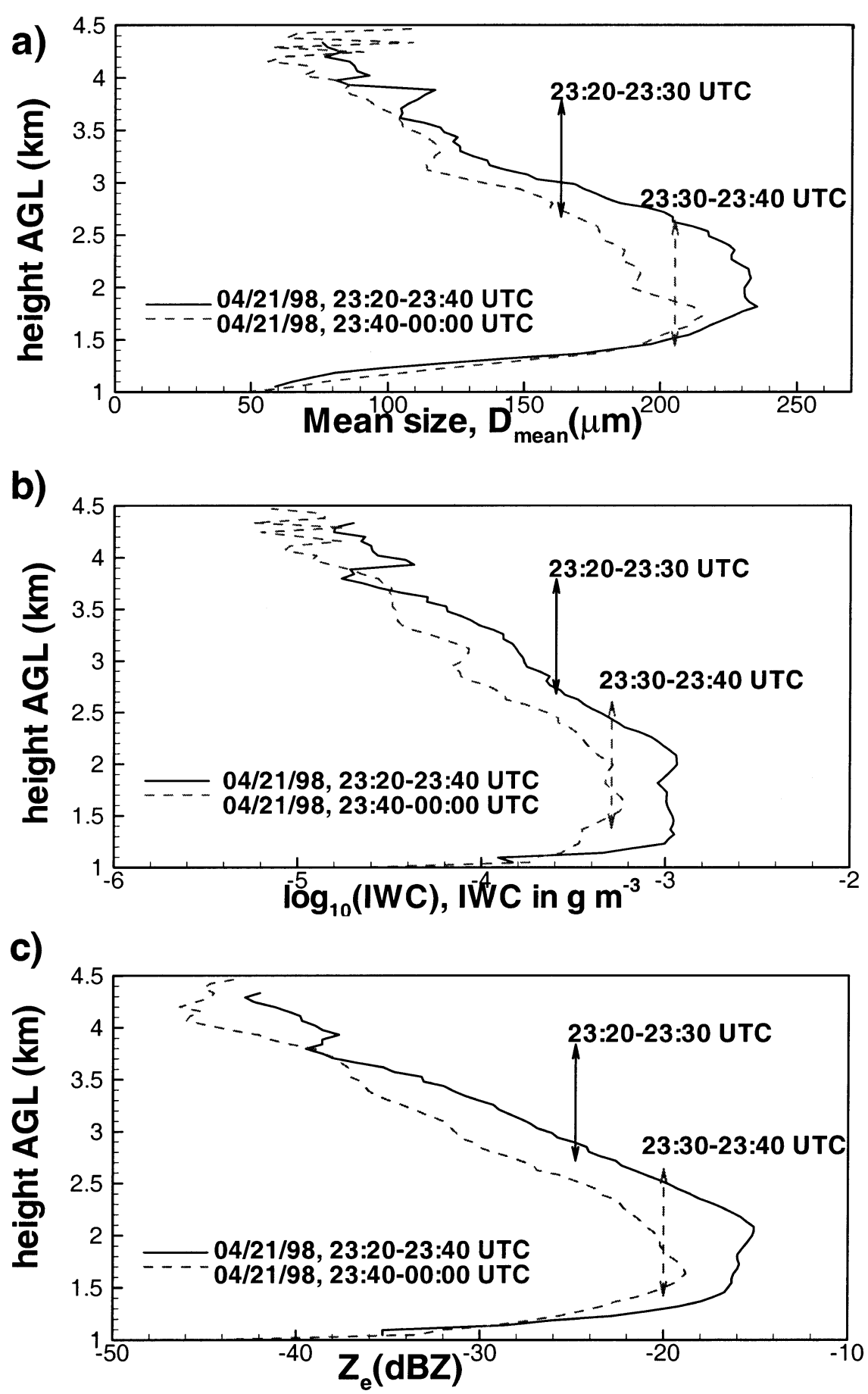

FIG. 8. Comparisons of in situ and remote estimates of (a) $D_{\text {mean }}$, (b) IWC, and (c) $Z_{e}$ for the observational case of 21-22 Apr 1998. Data correspond to the aircraft descent over the radar. In situ estimates are given by the arrows.

ments require robust methods that are applicable to a wide range of atmospheric conditions. The remote sensing method suggested here uses measurements from a vertically pointed cloud Doppler radar to retrieve vertical profiles of ice cloud water content and characteristic particle size (such as median or mean size, which describe the whole cloud particle size distribution). As the first step of the method, particle size information is inferred from the Doppler velocity measurements, which are averaged in 20-30-min intervals to ensure that the residual air motion contributions are small enough compared to the reflectivity-weighted particle 


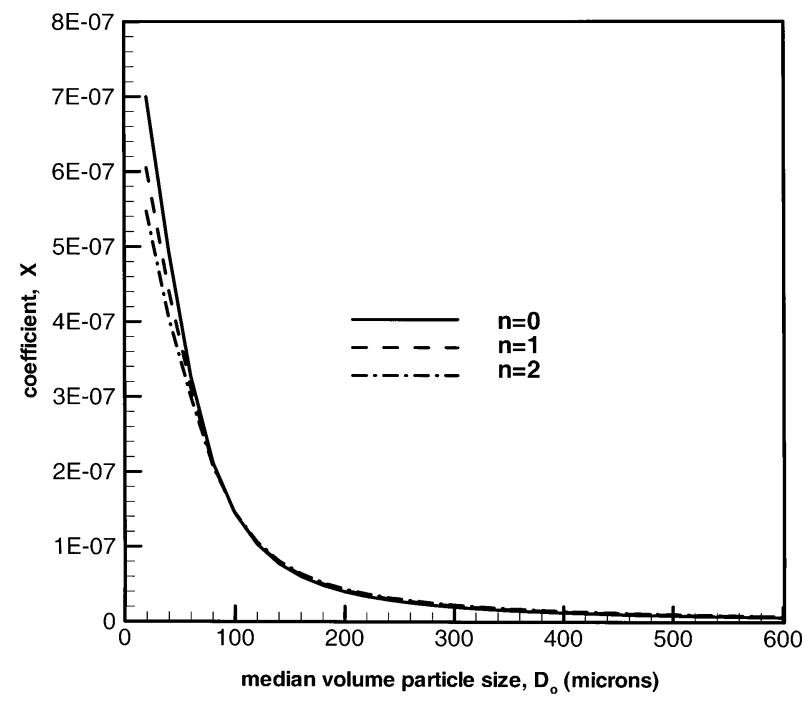

FIG. 9. Coefficient $X$ as a function of $D_{0}$ for different orders of the gamma-function particle size distribution $(n)$

fall velocities, $V_{z}$. The suggested correspondence between particle median volume size, $D_{0}$, and $V_{z}$ is fairly insensitive to variations of particle size distributions; it also accounts for the intrinsic correlation between the coefficients in fall velocity-size relations and characteristic particle sizes. The next step of the suggested remote sensing method is to retrieve the vertical profiles of cloud IWC from the measured profile of radar reflectivity and the profiles of $D_{0}$ estimated from Doppler velocity measurements. These retrievals are performed under the Rayleigh scattering assumptions, which are generally valid for most nonprecipitating and weakly precipitating ice clouds at $\mathrm{K}_{a}$-band radar frequencies. The retrievals account for changes in particle bulk density as a function of particle size. The estimated uncertainties of the suggested method are about $36 \%-40 \%$ for $D_{0}$ retrievals and about factor of $2(+100 \%,-50 \%)$ for IWC retrievals. The accuracy of the retrievals is expected to degrade somewhat for clouds that exhibit very low Doppler velocities (less than about $25-30 \mathrm{~cm}$ $\mathrm{s}^{-1}$ ) due to relative increase in vertical air motion contributions and also for clouds with very high Doppler velocities (greater than about $0.8-1 \mathrm{~m} \mathrm{~s}^{-1}$ ) due to gradual diminishing of the rate of fall velocity increase with particle size.

The Doppler velocity-reflectivity method suggested here has a much wider range of applicability to fairly homogeneous midaltitude ice-containing clouds compared to ground-based multisensor approaches (i.e., radar-lidar-, radar-radiometer-based methods) since the latter ones are mostly limited to pure-ice-phase clouds unobstructed by liquid layers. In mixed-phase clouds consisting of ice particles and small liquid drops, this method will provide information on the ice component of such clouds, since the contribution of small drops to the radar parameters is usually minor compared to that of ice particles due to significant differences in size. Another advantage of the Doppler velocity-reflectivity approach is the lack of uncertainties caused by the fact that remote sensors operating at significantly different wavelengths (e.g., radars and lidars) often see cloud geometrical boundaries differently. It should be mentioned, however, that often radar does not detect cloud parts with very small particles, which are detectable by lidar if they are not obstructed by liquid water layers.

The requirement of long time averaging of Doppler measurements results in a relatively crude temporal resolution of retrievals obtained with the Doppler velocityreflectivity method compared to the multisensor methods. However, for the purpose of long-term observations of cloud microphysical parameters in a statistical sense, this might be not regarded as a significant drawback, though it excludes a possibility of studying statistical characteristics with time steps smaller than the averaging time. It should be noted also that the applicability of the suggested remote sensing method is limited to observational situations with no strong updrafts and/or downdrafts, which could contaminate estimates of reflectivity-weighted cloud particle fall velocities.

The Doppler velocity-reflectivity method was applied to several observational cases from the FIRE ACE field experiment. Comparisons of retrieval results with cloud parameter estimates from aircraft in situ sampling during an aircraft descent over the radar showed generally good agreement. Remotely measured values of IWC and particle mean size, $D_{\text {mean }}$, were on average somewhat greater than ones from in situ estimates. The relative standard deviations between retrieved and in situ datasets were about $55 \%$ for IWC and $25 \%$ for $D_{\text {mean }}$, which is well within typical uncertainties of the remote and direct (in situ) approaches.

For a long observational case of pure-ice-phase cloud unobstructed by liquid layers, the results of the radaronly-based method suggested here were also compared with retrieval results obtained using the multisensor radar-radiometer method. The relative standard deviation between results of these two remote sensing methods was about $27 \%$ for $D_{\text {mean }}$ and $38 \%$ for IWC which, as mentioned above, is well within expected errors of the remote sensing methods.

\section{Recommendations and future plans}

The suggested method to estimate vertical profiles of ice cloud particle characteristic size and IWC using measurements of radar reflectivity and Doppler velocity can be run in a near-real-time mode when taking measurements. While running the ETL cloud-sensing instrumentation in the future, it is planned to use the results obtained with this method as the initial estimate, which can then be refined whenever the multisensor results are available. Although simple theoretical estimations of retrieval uncertainties and initial comparisons with in situ data and multisensor approaches (when the latter are 
applicable) indicate the usefulness of the suggested method, we plan to continue validation efforts for more diverse datasets. We plan to apply this method to the year-long SHEBA dataset. Microphysical retrieval results obtained with it will be compared with retrievals using the radar-radiometer method (for cloud observations when the multisensor approach is applicable) and available in situ data to assess whether any significant biases are present and whether the results from the two different remote sensing approaches are consistent given the estimated retrieval uncertainties.

Acknowledgments. This research was funded, in part, by the SHEBA Phase III Program and the NASA EOS Project Science Office. The authors are thankful to M. Shupe and T. Uttal for providing radar data.

\section{REFERENCES}

Atlas, D., S. Y. Matrosov, A. J. Heymsfield, M. D. Chou, and D. B. Wolff, 1995: Radar and radiation properties of ice clouds. $J$. Appl. Meteor., 34, 2329-2345.

Babb, D. M., J. Verlinde, and B. A. Albrecht, 1999: Retrieval of cloud microphysical parameters from $94-\mathrm{GHz}$ radar Doppler power spectra. J. Atmos. Oceanic Technol., 16, 489-503.

Brown, P. R. A., and P. N. Francis, 1995: Improved measurements of the ice water content in cirrus using a total-water probe. $J$. Atmos. Oceanic Technol., 12, 410-414.

Curry, J. A., and Coauthors, 2000: FIRE Arctic Clouds Experiment. Bull. Amer. Meteor. Soc., 81, 5-29.

Donovan, D. P., and A. C. A. P. van Lammeren, 2001a: Cloud effective particle size and water content profile retrievals using combined lidar and radar observations. 1. Theory and examples. J. Geophys. Res., 106 (D21), 27 425-27 448.

— content profile retrievals using combined lidar and radar observations. 2. Comparison with IR radiometer and in situ measurements in ice clouds. J. Geophys. Res., 106 (D21), 27 44927464.

Frisch, A. S., C. W. Fairall, and J. B. Snider, 1995: Measurement of stratus cloud and drizzle parameters in ASTEX with Doppler radar and microwave radiometer. J. Atmos. Sci., 52, 2788-2799.

Fu, Q., B. Carlin, and G. Mace, 2000: Cirrus horizontal inhomogeneity and OLR bias. Geophys. Res. Lett., 27, 3341-3344.

Heymsfield, A. J., and J. Iaquinta, 2000: Cirrus crystal terminal velocities. J. Atmos. Sci., 57, 916-938.

—, A. Bansemar, S. Lewis, J. Iaquinta, M. Kajikawa, C. Twohy, and M. Poellot, 2002: A general approach for deriving the properties of cirrus and stratiform ice cloud particles. J. Atmos. Sci., 59, 3-29.

Houghton, J. T., L. G. Meira Filho, B. A. Callander, N. Harris, A. Kattenberg, and K. Maskell, Eds., 1996: Climate Change 1995: The Science of Climate Change. Cambridge University Press, $572 \mathrm{pp}$

Intrieri, J. M., G. L. Stephens, W. L. Eberhard, and T. Uttal, 1993: A method for determining cirrus cloud particle sizes using lidar and radar backscatter technique. J. Appl. Meteor., 32, 10741082.

_ M. D. Shupe, T. Uttal, and B. J. McCarthy 2002: An annual cycle of Arctic cloud characteristics observed by radar and lidar at SHEBA. J. Geophys. Res., in press.

Kosarev, A. L., and I. P. Mazin, 1991: An empirical model of the physical structure of upper layer clouds. Atmos. Res., 26, 213228.
Liao, L., and K. Sassen, 1994: Investigation of relationships between Ka-band radar reflectivity and ice and water content. Atmos. Res., 34, 231-248.

Liu, C. L., and A. J. Illingworth, 2000: Toward more accurate retrievals of ice water content from radar measurements of clouds. J. Appl. Meteor., 39, 1130-1146.

Locatelli, J. D., and P. V. Hobbs, 1974: Fall speeds and masses of solid precipitation particles. J. Geophys. Res., 79, 2185-2197.

Mace, G. G., T. P. Ackerman, P. Minnis, and D. F. Young, 1998: Cirrus layer microphysical properties derived from surface-based millimeter radar and infrared interferometer data. J. Geophys. Res., 103, 23 207-23 216.

Matrosov, S. Y., 1997: Variability of microphysical parameters in high-altitude ice clouds: Results of the remote sensing method. J. Appl. Meteor., 36, 633-648.

, 1999: Retrievals of vertical profiles of ice cloud microphysics from radar and IR measurements using tuned regressions between reflectivity and cloud parameters. J. Geophys. Res., 104, $16741-16753$.

_ , and A. J. Heymsfield, 2000: Use of Doppler radar to assess ice cloud particle fall velocity-size relations for remote sensing and climate studies. J. Geophys. Res., 105, 22 427-22 436.

_ , T. Uttal, J. B. Snider, and R. A. Kropfli, 1992: Estimation of ice cloud parameters from ground-based infrared radiometer and radar measurements. J. Geophys. Res., 97, 11 567-11 574.

—, A. J. Heymsfield, J. M. Intrieri, B. W. Orr, and J. B. Snider, 1995: Ground-based remote sensing of cloud particle sizes during the 26 November 1991 FIRE cirrus case: Comparisons with in situ data. J. Atmos. Sci., 52, 4128-4142.

,,-- R. A. Kropfli, B. E. Martner, R. F. Reinking, J. B. Snider, P. Piironen, and E. W. Eloranta, 1998: Comparisons of ice cloud parameters obtained by combined remote sensor retrievals and direct methods. J. Atmos. Oceanic Technol., 15, 184-196.

, T. Uttal, A. J. Heymsfield, A. V. Korolev, and G. A. Isaac, 2000: Comparisons of remote and in situ measurements of cloud microphysical profiles in arctic clouds. Preprints, Fifth Int. Symp. on Tropospheric Profiling, Adelaide, Australia, ATRAD, 209211.

Mitchell, D. L., 1996: Use of mass- and area-dimensional power laws for determining particle terminal velocities. J. Atmos. Sci., 53, $1710-1723$.

Orr, B. W., and R. A. Kropfli, 1999: A method for estimating particle fall velocities from vertically pointing Doppler radar. J. Atmos. Oceanic Technol., 16, 29-37.

Platt, C. M. R., and A. C. Dilley, 1981: Remote sounding of high clouds. IV: Observed temperature variations in cirrus optical properties. J. Atmos. Sci., 38, 1069-1082.

Pruppacher, H. R., and J. D. Klett, 1978: Microphysics of Clouds and Precipitation. D. Reidel, 714 pp.

Ramanathan, V., R. D. Cess, E. F. Harrison, P. Minnis, B. R. Barkstrom, E. Ahmad, and D. Hartman, 1989: Cloud-radiative forcing and climate: Results from the Earth Radiation Budget Experiment. Science, 243, 57-63.

Rozenberg, V. I., 1972: Scattering and Extinction of Electromagnetic Radiation by Atmospheric Particles (in Russian). Hydrometeoizdat, $348 \mathrm{pp}$.

Sassen, K., 1987: Ice cloud content from radar reflectivity. J. Climate Appl. Meteor., 26, 1050-1053.

Sekelsky, S. M., W. L. Eclund, J. M. Firda, K. S. Gage, and R. E. McIntosh, 1999: Particle size estimation in ice-phase clouds using multi-frequency radar reflectivity measurements at 95, 33, and $2.8 \mathrm{GHz}$. J. Appl. Meteor., 38, 5-28.

Stephens, G. L., S. C. Tsay, P. W. Stackhouse Jr., and P. J. Flatau, 1990: The relevance of the microphysical and radiative properties of cirrus clouds to climate and climatic feedback. J. Atmos. Sci., 47, 1742-1753.

Shupe, M. D., T. Uttal, S. Y. Matrosov, and A. S. Frisch, 2001: Cloud water contents and hydrometeor sizes during the FIRE-Arctic Clouds Experiment. J. Geophys. Res., 106, 15 015-15 028. 